\title{
Relationship between knowledge and practice of breast self-examination among female workers in sokoto, nigeria
}

\begin{abstract}
Breast cancer is a devastating disease that has no immunizations yet, but can be prevented through early diagnosis and treatment with the help of Breast Self-Examination (BSE). There is evidence that women who correctly practice BSE monthly are more likely to detect lump at the early stages of its development and early diagnosis has been reported to produce good prognosis. This study will explore relationship between knowledge and practice of BSE among women in Sokoto. The study was conducted in Sokoto city among 400 educated women using cross sectional design. A structural questionnaire was used as an instrument for data collection via multistage sampling technique. Findings of this study show that majority of the participants had average knowledge of BSE but only one-third of the participants' practice BSE regularly. A significant positive relationship exist between knowledge and practice of BSE among women $(r=0.242, P=0.001)$. Therefore, there is need for the health workers to provide health education to women on breast cancer and promote breast self-examination among women.
\end{abstract}

Volume 9 Issue 3 - 2018

\author{
Abdurrahman Muhammad Sani,' Samira \\ Labaran Yau ${ }^{2}$ \\ 'Department of Nursing Sciences, College of Health Sciences, \\ Usmanu Danfodiyo University, Nigeria \\ ${ }^{2}$ Department of Nursing Sciences, Faculty of Medicine, Federal \\ University Birnin Kebbi, Nigeria
}

\begin{abstract}
Correspondence: Abdurrahman Muhammad Sani, Department of Nursing Sciences, College of Health Science, Usmanu Danfodiyo University, Sokoto, Sokoto State, Nigeria, Tel 234(0)8138043736, +60103194959, Email kickbray@yahoo.fr
\end{abstract}

Received: February 27, 20I8 | Published: May 07, 2018

\section{Introduction}

Cancer is a major cause of morbidity and mortality throughout the world, with about 14.1 million people newly diagnosed in 2012 and about 8.2 million people died from the disease worldwide in 2012. ${ }^{1}$ Breast Cancer is now the most common cancer affecting women worldwide $(25.2 \%)$, and the second leading cause of cancer deaths $(15 \%)$ in women. ${ }^{1}$ About half of the breast cancer cases and $60 \%$ of the deaths are estimated to occur in Middle and Low income Countries. ${ }^{2}$ Global cancer statistics indicate rising global incidence of breast cancer and the increase is occurring at a faster rate in populations of the developing countries, this is due to increase in population growth and ageing. ${ }^{1,2}$ In Sub-Saharan Africa, breast cancer has now become the most commonly diagnosed cancer among women, a shift from previous decades in which cervical cancer was the most commonly diagnosed cancer in many of these countries. ${ }^{1}$ The reasons for this shift are unknown but may include increases in the prevalence of risk factors for breast cancer such as early menarche, late childbearing, having fewer children, obesity, and increased awareness and detection, which are associated with urbanization and economic development., ${ }^{2,3}$

While very little can be done to limit the main causative risk factors. Breast Self-Examination remains the most effective measures for early detection of breast cancer as documented in epidemiological studies. ${ }^{4,5}$ Important advances have been made in strategies for early detection and in therapeutic interventions which may contribute to more favourable outcomes for breast cancer patients. ${ }^{4}$

Nigerian women are presenting with advanced stages at which time little or no benefit is derived from any form of therapy. ${ }^{6}$ The 5 -year survival of breast cancer in Nigeria is less than 10\% compared with over $70 \%$ in Western Europe and North America. ${ }^{7}$ Although there is strong evidence suggesting that older women in the developed countries are more likely to delay their presentation with breast cancer. There is data suggesting that factors related to women's knowledge and beliefs about breast cancer and its management may contribute significantly to medical help-seeking behaviours. ${ }^{8}, 9$

One potentially important strategy in reducing breast cancer mortality is breast cancer screening to achieve earlier detection of cancer. So, creating awareness which is a very important tool entails better screening of breast cancer. Early detection tests for breast cancer save thousands of lives each year, and even many more lives could be saved if more women and their health care providers took advantage of these tests. ${ }^{10,11}$ Following the guidelines for the early detection of breast cancer improves the chances of breast cancer diagnosis at an early stage and its successful treatment. ${ }^{10,12,13}$ However, none of these screening tests is $100 \%$ sensitive in detecting breast cancer. Therefore, it is often recommended that a combination of these techniques be used in the screening process (Allen et al., 2010). Lack of knowledge is the most important factor for anyone intending to conduct cancer screening tests. Thus, giving the right information about cancer and its screening methods to the high risk group may reduce their wrong beliefs. ${ }^{14}$

Avariety of screening methods are used to detectbreastabnormalities and potential malignancies. These include; Mammography, Ultrasonography, Magnetic Resonance Imaging (MRI), Clinical Breast Examination (CBE), and Breast Self-Examination (BSE). The main screening methods of breast cancer in Africa and other developing countries involve Breast Self-Examination, Clinical Breast Examination (CBE) and mammography. ${ }^{20,12,13}$ However, the sensitivity and specificity of each test varied. ${ }^{14}$

The sensitivity and specificity values of BSE may be difficult to determine. But in a study conducted by Wilke et al., (2009) discovered the sensitivity of BSE to be $58.3 \%$, and the specificity to be $87.4 \%$. This is comparable to that of MRI in detecting breast cancer. The sensitivity, Specificity and predictive value of BSE to detect breast cancer are more than that of Mammography and CBE. ${ }^{5}$ This is because in the study both BSE and MRI detect $43 \%$ each of the breast cancer while mammography and CBE detect $14 \%$ and $2 \%$ respectively. ${ }^{5}$ 
There are a number of advantages of performing a BSE, such as allowing women to gain a sense of control over their health and to become comfortable with their own breasts. ${ }^{14,15}$ Additionally, it is a simple, non-invasive procedure that can be performed by nonmedically trained individuals. Up to $70 \%$ of breast cancers are found by women performing BSE. ${ }^{16}$ The American Cancer Society recommends the use of BSE as a tool for breast cancer screening, stating that palpable lesions can be detected through BSE. The American Cancer Society also states that BSE can also help women recognize normal versus abnormal breast tissue. ${ }^{17}$ Although there are organizations that still recommend the practice of BSE, the use of this technique has come under scrutiny since newer screening technologies have been developed. ${ }^{14}$

For younger women, BSE is often the only method that is available for them to detect abnormal changes at an early stage due to inaccuracy and ineffectiveness of other screening tests and greater breast tissue density. ${ }^{18}$ Regular BSE is a cost-effective, convenient, private and simple method that does not require specific equipment. ${ }^{19}$ Despite these benefits, only $18 \%-36 \%$ of women perform BSE. ${ }^{18,20,21}$

Knowledge of BSE is important in the detection and diagnosis of breast cancer; more than $80 \%$ of the cancer patients detect their own tumour. ${ }^{22,23}$ This may be done either by chance, during BSE or accidentally through medical examination for other problems. ${ }^{22}$ The knowledge of BSE may lead to action which is translated into the practice of BSE. This shows the significance of the knowledge and the practice of BSE in the detection and diagnosis of breast cancer. The knowledge of BSE gives women opportunity to become aware of the normal shape and feeling of their breast. ${ }^{24}$ which serve as a guide in the detection of early breast changes.

Studies conducted in Malaysia, Iran, Ghana and Turkey revealed that majority of the women had inadequate knowledge of BSE. ${ }^{22,25-27} \mathrm{On}$ the other hand some studies revealed that majority of the women have adequate level of knowledge of BSE. A study conducted by Dahlui. ${ }^{28}$ to investigate rural women's knowledge of breast cancer and screening methods in Malaysia. The findings showed that majority $(52 \%)$ had moderate knowledge of BSE, while $26 \%$ and $21 \%$ had good and poor knowledge of BSE respectively. Though this study was conducted among educated women, the study involved only five questions to assess the women's knowledge of breast cancer and BSE. The study used interview method with a semi structured questionnaire to assess the knowledge of participants. Meanwhile, interview may not be the most suitable method of assessing knowledge because some women may not be able to provide good verbal response. Also, Interview is associated with bias and difficulty in achieving reliable and valid results. ${ }^{29,30}$

In Nigeria many studies had reported inadequate knowledge and low level of practice of BSE among women. In a study conducted in Rivers state of Nigeria only $39.56 \%$ had good knowledge of Breast cancer and BSE. ${ }^{24}$ This is also similar to the study conducted in Edo state of Nigeria among community dwellers which shows that only $22.9 \%$ of the respondents had good knowledge of BSE. ${ }^{31}$ However, a study conducted by Oluwole..$^{32}$ among health professionals in Ondo state of Nigeria indicated that $80 \%$ had good knowledge of BSE. This is not surprising because health professionals had formal training on breast cancer and BSE.

There is no much difference in the knowledge level of university students with other women in Nigeria. A study conducted among undergraduate students of Ahmadu Bello University Zaria, revealed that only $37.3 \%$ of the respondent could correctly describe BSE. ${ }^{33}$ The study also found that the knowledge level varies across the different levels and courses of study. Students of health related disciplines have higher knowledge level than others.

Some studies conducted in Nigeria also reported good knowledge of BSE among women. A study conducted by Olowokere ${ }^{34}$ revealed that $56.7 \%$ of the women in some rural communities in southern Nigeria had good knowledge of BSE. This may not be surprising because women in the southern part of Nigeria have more education and information facilities than those in the north. Though the study employed a small sample of women and conducted among women attending health facilities. Therefore, the level of knowledge of BSE varies among women depending on the amount of information received and other variables. ${ }^{8}$ The knowledge level among women may range from limited or poor to good knowledge of BSE.

The practice of BSE involves performing the procedure with the aim of detecting a lump or any breast changes. Performing BSE gives women the opportunity to assess their breast consistency and report any changes to the hospital immediately. ${ }^{35,24}$ Through BSE women can detect the presence of a lump in the breast ${ }^{36}$ some are confirmed by their spouses before reporting to the hospital..$^{22}$ This emphasizes the importance of practicing BSE, more than clinical breast examination because even when some women detect the presence of lump in their breast, physicians in the hospital could not confirm the lump. ${ }^{22,5}$

There are variations in the level of practice of BSE among women. Generally, the frequency of regular BSE practice is low among women. Studies conducted in Malaysia, Iran and Turkey revealed that there is low practice of BSE among women despites its simplicity. ${ }^{25-27}$ In Thailand, $61.8 \%$ have ever practiced BSE but only $33 \%$ practice BSE regularly among Thai women diagnosed with breast cancer. ${ }^{36}$ In comparison, the practice of BSE among women in Kuwait is lower than that of women in Thailand. Only $7.1 \%$ of female teachers in Kuwait practice BSE regularly ${ }^{37}$ and $12 \%$ of women attending Primary Health Centre in Kuwait practice BSE regularly. But the case is also different in United States of America where more than $80 \%$ of African American women practiced BSE.

In Nigeria many studies had reported low level of practice of BSE among women. In a study conducted in Rivers state of Nigeria only $28.94 \%$ practiced BSE. ${ }^{24}$ This is also similar to the study conducted in Edo state of Nigeria among community dwellers which showed that only few women practiced BSE (24.4\%) monthly. ${ }^{31}$ Meanwhile, $50 \%$ of health professionals in Ondo state of Nigeria practiced BSE monthly. ${ }^{32}$ In a related study, $27.3 \%$ of women in Oyo state practiced BSE but only $11.7 \%$ practiced it regularly. ${ }^{34}$

Moreover, the reasons for the low rate of practice of BSE among women include; fear of finding that they have breast cancer, fear of finding a lump, inadequate knowledge regarding how to perform BSE, forgetfulness, dislike to touch breast, absence of breast complaints and lack of awareness about what to do if a lump is found. ${ }^{37}$ These barriers can be eliminated through BSE education to women.

The practice of BSE is the application of the knowledge of BSE. The practice indicates the amount of knowledge of BSE a woman possess. Women with satisfactory knowledge of BSE are more likely to practice BSE because a woman cannot practice what she does not know. Studies have reported significant association between the knowledge of BSE and the practice of BSE. $28,31,36,38$ This shows that women that had adequate knowledge of BSE are more likely to practice BSE than women with inadequate knowledge of BSE. AlAzmy and colleagues, ${ }^{38}$ reports that $65 \%$ of women that practice BSE 
have adequate knowledge of BSE. These findings may be so because lack of knowledge of BSE may serve as a barrier to the practice of BSE. Therefore, this study will explore the relationship between knowledge and practice of BSE among women in Sokoto, Nigeria.

\section{Materials and methods}

The study employs quantitative descriptive cross-sectional design to examine relationship between knowledge and practice of BSE among women in Sokoto, Nigeria. Sokoto is the capital city of Sokoto state and one of the thirty six (36) states of the Federal Republic of Nigeria. The state has a land mass of about 32,000Sqkm with a population of $4,427,760$ according to 2006 Census. Sokoto is a city located at the extreme North-Western part of Nigeria, near the confluences of Sokoto River and Rima River. It's the modern day capital city of Sokoto state and the Seat of the Caliphate: The capital of the Nigerian Muslim leader; the Sultan of Sokoto. Sokoto town is made up of four Local Government Areas of Sokoto state: Sokoto North, Sokoto South, Wamakko and Dange-Shuni. Sokoto city had one teaching hospital, one specialist hospital, one orthopaedic hospital, two women and children hospitals and several private hospitals and Primary Health Centres. Sokoto city had several educational institutions such as two universities, one polytechnic, and one college of education, two Schools of Nursing and two schools of midwifery. Sokoto town has a population of 427, 760. Sokoto has several areas and the data was collected in the following areas: Mabera, Farfaru, Runjin Sambo, Shuni, and Gawon Nama. Mabera is in Sokoto South Local Government, Farfaru in Wamakko Local Gaverment, and Runjin Sambo in Sokoto North Local government and Shuni in Dange-Shuni Local Government.

The target population of the study was women of Sokoto city who are within the reproductive age group. According to National Population and Census Commission of Nigeria (2006), women of childbearing age constitute $22 \%$ of the population. The population of Sokoto town is: 427,760 . But 94,107 is the target population which represent $22 \%$ of the population of Sokoto city.

A sample size of 400 was chosen using online sample size calculator - Raosoft ${ }^{\circledR}$, which calculate the minimum effective sample size of 383 at $95 \%$ confidence interval and $5 \%$ margin of error using 94,107 as the target population. A multistage sampling technique was employed in this study; which involved the following sampling methods:

a. Cluster sampling of Sokoto into the existing cluster of four Local Government areas of Sokoto.

b. Simple random sampling of one area from each Local Government area of Sokoto

c. Systematic sampling of households to get respondents from each selected area of Sokoto city.

Structured questionnaire developed for this study after extensive review of literature was used as an instrument for data collection. The questionnaire consisted of thirty three (33) items with close ended questions. The knowledge sections consist of 20 questions. Two marks each for any correct answer and zero for any wrong answer or "I don't know." Participant scores of 0-19, 20-29 and 30-40 signifies inadequate knowledge, average knowledge and good knowledge respectively. The questionnaire was piloted among 30 women of Uguwar Rogo area of Sokoto, which have similar characteristics with the study setting. This is done to assess the validity and reliability of the instrument. The piloted questionnaire was analysed to calculate the Cronbach's alpha coefficient. The Cronbach's alpha coefficient ranges from 0.70 to 0.80 for different sections of the questionnaire.

The collected data was analysed using Statistical package for Social Sciences (SPSS version 20.0). Pearson $r$ was used to assess the relationship between the knowledge and practice of BSE. All tests were conducted with a confidence level of $95 \%$ and a significant level of 0.05 .

Ethical approval was sought out from Noguchi Memorial Institute for medical research (NMIMR), University of Ghana. The participants were informed that participation will be voluntary and participants have the right to withdraw from the study at any time. There are no risks involved in completing the questionnaire and no cost will be incurred by participation in the study. A potential benefit of participation is that participant will be able to explore their views regarding BSE and may possibly influence other women to do the same. Informed consent was obtained from the participants by signing the consent form after providing the participants with information about the purpose of the study, risk and benefit.

\section{Results}

\section{Knowledge of breast self-examination}

The knowledge scores of the respondents had been categorized to assess the level of knowledge of the respondents on BSE. Table 1 describes the respondents' level of knowledge of BSE. Majority of the respondents (45.4) had average level of knowledge of BSE, approximately thirty percent (29.6) had good knowledge of BSE and only $25.0 \%$ of the respondents had in-adequate knowledge. These indicate that the respondents had average level of knowledge of BSE.

Table I Level of knowledge of Breast Self-Examination

\begin{tabular}{llll}
\hline Level of knowledge & Scores & frequency & Percentage \\
\hline In-adequate knowledge & $0-19$ & 98 & 25 \\
Average knowledge & $20-29$ & 178 & 45.4 \\
Good knowledge & $30-40$ & 116 & 29.6 \\
Total & & 392 & 100 \\
\hline
\end{tabular}

\section{Practice of breast self-examination}

Table 2 indicates the respondents' practice of BSE. Majority $(89.8 \%)$ of the respondents had information about the practice of BSE. Majority $(46.6 \%)$ of the respondents received their information from health workers and only $2.0 \%$ received information from internet.

Moreover, approximately sixty five percent $(65.3 \%)$ of the respondents practiced BSE. Meanwhile, among $65.3 \%$ of the respondents that practiced BSE, only $52.7 \%$ practiced BSE monthly which represented only $34.4 \%$ of the total respondents. The percentage of the respondents that did not practice BSE gave reasons for not performing BSE as follows: that they did not know how to perform BSE, never heard any information about BSE, they did not have time to perform BSE and finally they thought it was unnecessary to do BSE as indicated in Table 2.

\section{Relationship between knowledge of BSE and practice of BSE}

The relationship between knowledge and the practice of BSE was tested using Pearson Product-Moment Correlation Coefficient (r). This is because both the knowledge of BSE and the practice of BSE were measured on at least interval scale. The statistical analysis conducted using Pearson $r$ established a significant relationship 
between the knowledge of BSE and practice of BSE among women. A weak significant positive relationship exists between the knowledge and the practice of BSE $(r=0.242, P=0.001)$ as presented in Table 3 . This indicates that a unit increase in the knowledge of BSE may produce corresponding increase in the practice of BSE.

Table 2 Practice of Breast Self - Examination

\begin{tabular}{|c|c|c|c|}
\hline Variable & & Frequency & percentage \\
\hline \multirow{6}{*}{$\begin{array}{l}\text { Information on } \\
\text { the practice of } \\
\text { BSE }\end{array}$} & Yes & 352 & 89.8 \\
\hline & No & 40 & 10.2 \\
\hline & Total & 392 & 100 \\
\hline & Health workers & 164 & 46.6 \\
\hline & Mass media & 108 & 30.7 \\
\hline & Religious Org. & 18 & 5.1 \\
\hline \multirow{6}{*}{$\begin{array}{l}\text { Source of } \\
\text { information }\end{array}$} & Books/Journals & 16 & 4.5 \\
\hline & Internet & 7 & 2 \\
\hline & Nig Cancer Society & 14 & 4 \\
\hline & Family and Friends & 25 & 7.1 \\
\hline & Total & 352 & 100 \\
\hline & Yes & 256 & 65.3 \\
\hline \multirow{4}{*}{$\begin{array}{l}\text { Respondents } \\
\text { practice of BSE }\end{array}$} & No & 136 & 34.7 \\
\hline & Total & 392 & 100 \\
\hline & Monthly & 135 & 52.7 \\
\hline & Quarterly & 18 & 7 \\
\hline \multirow{4}{*}{$\begin{array}{l}\text { Respondents' } \\
\text { frequency of } \\
\text { practice of BSE }\end{array}$} & Bi-annually & 8 & 3.1 \\
\hline & Annually & 22 & 8.7 \\
\hline & Once in a while & 73 & 28.7 \\
\hline & Total & 256 & 100 \\
\hline \multirow[t]{3}{*}{$\begin{array}{l}\text { Respondents' } \\
\text { reasons for not }\end{array}$} & Never heard of BSE & 30 & 22.1 \\
\hline & Embarrassing to do & 12 & 8.9 \\
\hline & Don't know how to do & 34 & 25 \\
\hline \multirow{4}{*}{ Practicing BSE } & Do not have time & 30 & 22.1 \\
\hline & Wrong to touch breast & 10 & 7.3 \\
\hline & Unnecessary to do & 20 & 16.6 \\
\hline & Total & 136 & 100 \\
\hline
\end{tabular}

Table 3 The relationship between knowledge and practice of BSE

\begin{tabular}{ll}
\hline Variable & Practice of BSE \\
\hline Knowledge of BSE & $0.242^{*}$ \\
\hline
\end{tabular}

$\mathrm{NB}, *$ significant value at 0.05 .

\section{Discussion}

\section{Knowledge of breast self-examination}

The knowledge of Breast cancer and BSE is very important in the early detection and diagnosis of breast cancer. This is because $80 \%$ of the respondents detect breast cancer by themselves either through regular BSE, by chance or accidentally through medical examinations. ${ }^{22,23}$ Findings of this current study show that $45.4 \%$ of the respondents had average knowledge and 29.6\% had good knowledge of Breast cancer and BSE. This suggests that many women in Sokoto have at least average knowledge of BSE. This is similar to the findings of Dahlui. ${ }^{28}$ which showed that $52 \%$ and $21 \%$ of the rural women in Malaysia had moderate and good knowledge of breast cancer and BSE respectively. This is also supported by the findings of Olowokere. ${ }^{34}$ which show that $52.7 \%$ of the rural women in Southern Nigeria had good knowledge of Breast cancer and BSE. This is also similar to the findings of the Alharbi, ${ }^{37}$ that more than fifty percent of the female teachers in Kuwait had adequate knowledge of BSE. However, these findings are in contrast with the findings of
Bellgam and Buowari. ${ }^{24}$ that more than sixty percent of the women in Rivers state of Nigeria had in-adequate knowledge of breast cancer and BSE. Similarly, the findings of this study contradict the findings of Okobia. ${ }^{31}$ among community dwellers in Edo state, Nigeria, that only $22.9 \%$ of the respondents had good knowledge of BSE. The high prevalence of average knowledge level of the women in this study may be due to the fact that Sokoto is the capital city of Sokoto state where healthcare facilities are available and women can have easy access to the healthcare resources. Also, the fact that women in this study are educated which may probably made them gain easy access to information about breast cancer and BSE.

\section{Practice of breast self-examination}

The practice of Breast Self-Examination gives a woman the ability to become breast aware and the opportunity to detect any changes in her breast and report to the hospital early which may influence the treatment decision and the prognosis of breast cancer. The practice of BSE reflects the practical application of the knowledge of BSE. Findings of this study indicate that more than sixty five percent of the respondents practiced BSE but only about thirty four percent practiced BSE regularly. This finding is consistent with the findings of Bilge and Keskin. ${ }^{39}$ in Turkey, Burangruangrote ${ }^{36}$ in Thailand, and Dahlui. ${ }^{28}$ in Malaysia. According to these authors, majority of women practiced BSE but only few practice BSE regularly. Similarly, in Nigeria the practice of BSE was high among health professionals in Ondo State. ${ }^{32}$

On the contrary, This finding does not support the findings of Bellgam \& Buowari. ${ }^{24,25,34,40}$ that only few women practiced BSE despites BSE being a simple procedure. The increase in the percentage of women that practiced BSE in this study may be due to increased knowledge of BSE among women in this study and the influence of education in providing behavioural change because all the respondents had formal education.

The present study also found that women who did not practice BSE reported reasons for their non-practice as lack of knowledge and information on how to do the procedure, lack of time, and BSE being an embarrassing procedure. Others thought that it was wrong to touch their breast and unnecessary to do BSE. These reasons are similar to the findings of Alharbi et al. ${ }^{37}$ in which female teachers reported lack of knowledge, dislike to touch their breast, fear of finding a lump and forgetfulness as the reasons for non-performance of BSE. These reasons suggest that there is the need for health workers to intensify their efforts toward providing women with the information on breast cancer and BSE in order to increase the regular practice of BSE and to correct their misconceptions about breast cancer and BSE.

\section{Relationship between knowledge and practice of breast self-examination}

The knowledge of BSE may influence the practice of BSE among women. Findings of this study revealed that a significant positive relationship exist between the knowledge of BSE and the practice of BSE. This means that as the knowledge of women on BSE increases the practice of BSE may likely increases. This finding may not be surprising because the study found that seventy percent of women have average level of knowledge of BSE and more than sixty five percent practiced BSE. This finding concurs with the findings of Al-Azmy et al. ${ }^{38}$ in Kuwait and Okobia et al. ${ }^{31}$ among women in Edo state of Nigeria, who reported that women who have adequate knowledge of BSE are more likely to practice BSE than women who have inadequate knowledge of BSE. Therefore, it may be inferred that 
women cannot practice BSE if they do not have adequate knowledge of BSE. ${ }^{41}$

\section{Conclusion}

Breast Self-Examination is a process of providing health promotion and preventing breast cancer through early detection and diagnosis. The findings of this study revealed that majority of the women had average knowledge of BSE but the practice of BSE among women remains low and a significant positive relationship exists between the knowledge and the practice of BSE among women. Therefore, there is need to provide more effective health educational activities to women in order to promote regular practice of BSE among women in Sokoto. There is also need to conduct an interventional study on the effect of educational programme on the knowledge and practice of BSE among women in both urban and rural communities.

\section{Acknowledgements}

None.

\section{Conflicts of interest}

The author declares that they do not have any conflicts of interest.

\section{References}

1. World Health Organization. The World Cancer Biennial Report. Geneva: WHO Press; 2014.

2. Jemal A, Bray F, Forman D, et al. Cancer Burden in Africa and Opportunities for Prevention. Cancer. 2012;118(18):4372-84.

3. Mackay J, Jemal A, Lee NC, et al. The Cancer Atlas. Atlanta: ACS Inc; 2006.

4. Boulos S, Godallah M, Neguib S. Breast Screening in the emerging world. High prevalence of Breast Cancer in Cairo, Egypt. Breast J.2005;14(5):340-6.

5. Wilke LG, Broadwater G, Rabiner S, et al. Breast Self-Examination: Defining a cohort still in need. The American $J$ Surgery. 2009;198(4):575-79.

6. Agbo PS, Khalid A, Oboirien M. Clinical Presentation, Prevalence and Management of Breast Cancer in Sokoto, Nigeria. J Women's Health Care. 2014;3:149.

7. Adebamowo CA, Ajayi OO. Breast cancer in Nigeria. West Afr J Med. 2010;19(3):179-91.

8. Odusanya OO, Tayo, O. Breast cancer knowledge, attitudes and practice among nurses in Logos, Nigeria. Acta Oncol. 2001;40(7): 844-8.

9. Ohaeri BM. A review of issues in Breast Cancer. In: Adejumo PO, Adejumo AO, editors. Current Trends and Issues in Nursing in Nigeria. Ibadan: Ibadan University press; 2009.

10. American Cancer Society. Breast cancer: early detection. Atlanta: Cancer Care; 2011.

11. Ghodsi Z, Salehi A, Hojjatoleslami S. Knowledge of Iranian women about warning signs and risk factors for breast cancer. Procedia-Social and Behavioural Sciences. 2013;93:343-48.

12. Komen SG. Brest self-awareness among women for breast cancer detection. J Breast Cance. 2011;93(2):523-36.

13. Rosen L, Rosen G. Breast Cancer: Early Detection: The importance of finding breast cancer early. Atlanta, American Cancer Society Inc; 2011.

14. Allen TL, Van Groningen BJ, Barksdale DJ, et al. The Breast SelfExamination Controversy: What Providers and Patients Should Know? International J Nursing Practice. 2010;6(6):444-51.
15. Thornton H, Pillarisetti RR. Breast awareness and breast selfexamination are not the same. What do these terms mean? Why are they confused? What can we do? European J cancer. 2008;44(15):2118-21.

16. Akhigbe AO, Omuemu VO. Knowledge, attitudes and practice of breast cancer screening among female health workers in a Nigerian urban city. BMC Cancer.2009;9:203.

17. American Cancer Society. Breast Cancer Facts and Figures 2013 2014. Atlanta: American Cancer Society Inc; 2013.

18. Sani MA, Naab F. Relationship between Age and Breast SelfExamination among Women in Nigeria. IOSR-JNHS. 2014;3(6):34-39.

19. Oztuek M, Engin VS, Kisioglu AN. The practice of breast selfexamination among women at Gulistem district of Isparta. Eastern $J$ Medicine. 2010;4(2):47-50.

20. Bilge U, Keskin A. Breast cancer screening knowledge in a Turkish population: Education is necessary. Procedia-Social \& Behavioural Sciences.2014;116:1861-1863.

21. Sani MA, Naab F, Aziato L. Influence of Educational Level on Knowledge and Practice of Breast Self-Examination among Women in Sokoto, Nigeria. J Basic \& Clinical Reproductive Science, 2016;5(2):1-7.

22. Aziato L, Clegg-Lamptey JN. Breast cancer diagnosis and factors influencing treatment decisions in Ghana. Health Care for Women International. 2014;36(5):543-57.

23. Loh SY, Chew SL. Awareness and Practice of Breast Self-Examination among Malaysian Women with Breast Cancer. Asian Pacific J Cancer Prev. 2011;12(1):199-202.

24. Bellgam HI, Buowari YD. Knowledge, Attitude and Practice of Breast Self -Examination among Women in Rivers State, Nigeria. The Nigerian Health J. 2012;12(1):16-18.

25. Akhtari-Zavare M, Juni MH, Manaf RA, et al. Knowledge on Breast Cancer and practice of Breast Self-Examination among selected Female University Students in Malaysia. Medical and Health Science J.2011;12(3):49-56.

26. Gursoy A, Yiğitbas C, Y1lmaz F, et al. The effect of peer education on university students' knowledge of breast self-examination and health beliefs. J Cancer Educ. 2009;24(4):331-333.

27. Hajian S, Vakilian K, Najabadi KM, et al. Effects of Education Based on the Health Belief Model on Screening Behavior in High Risk Women for Breast Cancer in Tehran, Iran. Asian Pacific J Cancer Prev. 2011;12(1):49-54

28. Dahlui M, Gan DEH, Taib NA, et al.Breast screening and health issues among rural females in Malaysia:How much do they know and practice? Pre Med. 2013;57 Suppl:S18-20.

29. Brewerton P, Millward LJ. Organizational Research Methods. London: Sage Publications; 2001.

30. Ofori R, Dampson DG. Research Methods and Statistics using SPSS. Kumasi: Payless Publication Ltd; 2011.

31. Okobia M, Bunker $\mathrm{CH}$, Okonofua FE, et al. Knowledge, attitude and practice of Nigerian women towards breast cancer: A cross-sectional study. World J Surgical Oncology. 2006;4:11.

32. Oluwole OC. Awareness, Knowledge and Practice of BreastSelf Examination amongst Female Health Workers in a Nigerian Community. Sudan JMS. 2008;3(2):99-104.

33. Gwarzo UMD, Sabitu K, Idris SH. Knowledge and practice of BSE among Female Undergraduate students of ABU Zaria, Northern Nigeria. Annals of African Medicine. 2009;8(1):55-58.

34. Olowokere AE, Onibokun AC, Oluwatosin AO. Breast cancer knowledge and screening practices among women in selected rural communities of Nigeria. J Public Health and Epi. 2012;4(9):238-245. 
35. Abdel-Fattah M, Zaki A, Bassili A. El-Shady H, et al. Breast Selfexamination practice and its impact on breast cancer diagnosis in Alexandria, Egypt. East Mediterranean Health J.2010;6(1):34-40.

36. Buranaruangrote S, Sindhu S, Mayer DK, et al. Factors influencing the stages of breast cancer at the time of diagnosis in Tha women. Collegian.2014;21(1):11-20.

37. Alharbi NA, Al-Shammari MS, Almutari BM, et al. Knowledge awareness and practices concerning breast cancer among Kuwait Female Teachers. Alexandria J Medicine. 2012;48(1):75-82.

38. Al-Azmy SF, Alkhabbaz A, Almutawa HA, et al. Practicing breast self-examination among women attending primary health care in Kuwait. Alexandria J Medicine.2013;49(3):281-86.

39. Bilge U, Keskin A. Breast cancer screening knowledge in a Turkish population: Education is necessary. Procedia-Social \& Behavioural Sciences.2014;116:1861-63.

40. Ghodis Z, Hojjatoleslami S. A Survey about educational needs of Breast Cancer and BSE in Iranian Women. Procedia-Social \& Behavioural Sciences.2012;46:2561-65.

41. Registe MF, Porterfield SP. Health Beliefs of African American women on BSE. American College of Nurse practitioners. 2012;8(6):446-51. 